\title{
Medical Students' Perception on Joining Military Medical Services: A Mixed Method Study
}

\author{
Bipin Kumar Shrestha ${ }^{1}$ and Rashmi Shrestha ${ }^{2}$
}

${ }^{1}$ Department of Physiology, Nepalese Army Institute of Health Sciences, Sanobharyang, Kathmandu, Nepal

${ }^{2}$ Department of Pharmacology, Nepalese Army Institute of Health Sciences, Sanobharyang, Kathmandu, Nepal

\begin{abstract}
Introduction: Currently, in Nepal there are 19 Medical Colleges, most of them under Tribhuvan University and Kathmandu University. Nepalese Army Institute of Health Sciences (NAIHS) is not-for-profit organisation run by Nepal Army Welfare Fund, affiliated to Tribhuvan University. Excluding the medical graduates from abroad there are around 1500 doctors graduating from Nepal every year. After graduation they have the options joining as a Medical Officer in hospitals around Nepal or go abroad. Joining the Military Medical services seems appealing. However the options are broadening with the jobs in the private and other sectors becoming more lucrative. This study attempts to explore the perception of medical students on joining the Military Medical Services.

Methods: The study was conducted during November 2016 to December 2017 among first and second year MBBS students of NAIHS. Comprehensive information about becoming a Military doctor in Nepal Army Medical Corps was provided. Student perceptions about joining Military Medical Services were studied using the semi-structured questionnaire. Informed written consent was taken from the students for the study.

Results: From the total (204) respondents, 64.7\% (132) chose to join the Military Medical Services. Among the responses, serving the nation, job security and opportunity for career development were the most chosen. Responses like preferring private practice, less pay/salary, and deployment consideration were the reasons for not choosing to join the Military Medical Services.

Conclusions: Job as a Military Doctor seems attractive to majority of the Medical students. Male and Female medical students are equally interested towards becoming a military doctor in Nepal Army.

Key words: appealing; medical education; military doctor; NAIHS
\end{abstract}

Correspondence: Bipin Kumar Shrestha, Department of Physiology, Nepalese Army Institute of Health Sciences, Sanobharyang, Kathmandu, Nepal. E-mail: bipin.shrestha@naihs.edu.np.

DOI: http://dx.doi.org/10.3126/mjsbh.v19i1.22044

Submitted on: 2018-12-17

Accepted on: 2019-07-17 


\section{INTRODUCTION}

Currently there are 19 medical colleges in Nepal. Institute of Medicine of Tribhuvan University and Kathmandu University are major institutions providing medical education in Nepal with their affiliated medical colleges. Two other deemed universities; B. P. Koirala Institute of Health Sciences and Patan Academy of Health Sciences also contribute in producing medical doctors in Nepal. Thus, approximately 1500 medical students graduate each year. Adding to this number is the medical graduates from China, Philippines, Bangladesh, Pakistan and others. After graduation they have the options joining as a Medical Officer in hospitals around Nepal. They can compete for civil services of Nepal Government, Nepal Army Medical Corps, Nepal Police Hospital or any other Private Hospitals in Nepal. Also many of the graduates opt to go abroad like USA, Australia, Canada etc.

From the various options, Government Jobs in Nepal are attractive. However the options are broadening with the jobs in the private and other sector becoming more lucrative. ${ }^{1}$ This may be because of many reasons, the explanation of which is beyond the scope of this study. Nevertheless, there are many medical graduates who still want to work for the country and serve the citizens of Nepal. For these graduates, Nepal Army Medical Corps (NAMC) is one of the platforms.

Nepalese Army Institute of Health Sciences (NAIHS) affiliated to Tribhuvan University is a Medical College run by Nepal Army Welfare Fund. This College is located in Bhandarkhal Kathmandu and is a not for profit organisation which is committed to quality medical education, excellence in healthcare services for the nation and research.

In this study an attempt is made to know the perception of first and second year medical students about becoming a Military Doctor in Nepalese Army after the graduation from NAIHS. The relevance of this study would be that we will know about the appealing and unappealing factors for joining Nepalese Army Medical Services. In the past, few doctors who had joined have left after joining NAMC. Hence this study will help to know the percentage of NAIHS graduates who choose to join the Army Medical Services and the various appealing and unappealing factors. This would help the institution to focus and facilitate the appealing factors to attract, motivate and retain the Medical Doctors.

This study was conducted with the objectives of finding out what percentage of first and second year medical students choose to join the Nepal Army Medical Corps after graduation and to find out what is appealing and unappealing about becoming a Military Doctor in Nepal Army.

\section{METHODS}

The study was conducted during November 2016 to December 2017 among first and second year MBBS students of our college. The authors using inputs from the literature prepared the questionnaire. The questionnaire was asked to review by fourth year students in order to test for the ease of comprehension. The aims and objectives of the study was explained to the respondent students and their written consent obtained. Year of study and gender were noted. Student perceptions about joining NAMC after graduation were studied using the semi-structured questionnaire. All first year and second year MBBS students of NAIHS were included in the study.

Before the questionnaire was given to the respondent students, comprehensive information regarding the Job as a Military Doctor in Nepal Army Medical Corps was provided as follows:

1. Joining Eligibility: At the time of application he/ she must be MBBS or BDS graduate registered in the Nepal Medical Council. Age should be less than 28 years with height at least 5 feet 2 inches. The applicant must be a Nepali Citizen.

2. Recruiting Process: It takes around a month or two for the whole process to complete. The applicant should go through general physical examinations and then physical fitness tests (pushups, chin-ups, 200 meter and 2.4 kilometre running). After this they need to appear for the written examinations (both general knowledge and 
Medical). Following this, there will be interviews taken from recruitment board first and from senior consultant doctors later. After each tests or assessments mentioned above the names of the successful candidates will be displayed. Only the successful candidates will proceed to the next assessment. Lastly the final results of all the above assessments will be displayed and the successful candidate is recruited.

3. Military training: After the recruitment the candidate need to go through Technical Officers Basic Course at Nepal Military Academy, Kharipati. The course lasts 12 weeks, which is designed to teach basic soldiering skills in order to enable professional individuals to integrate fully with the larger Army. This includes regular physical exercise, navigation, leadership skills, drills, weapon handling and marksmanship. In addition there will be several weeks of indoor and outdoor exercises.

4. Military ranks: The doctor is commissioned as a lieutenant. He/she will be promoted according to rules and regulations for Technical Officers in Nepal Army. The highest rank attainable for a Doctor as of now is Major General.

5. Roles and responsibilities: As a General Duty Medical Officer (GDMO) the roles and responsibilities are as follows:

a. Day and night duties in the Emergency department in rotation.

b. Postings in Field Ambulances in different areas of the country.

c. Periodic health checks of the Army Personals.

d. Participate as a medical support in Military outdoor exercises.

e. Standby duties for VIP/VVIPs.

f. Medical support during disaster, natural calamities and epidemics.

g. Civil-Military Cooperation-Medical Camps in various parts of the country.

h. UN Peacekeeping mission: Pre deployment medical check ups and establishment of Level 1 Hospital in Mission area.
6. Salary and benefits: Commissioned, as Lieutenant the salary is equivalent to $3^{\text {rd }}$ class officer of Nepal Government Civil hospitals, which increases accordingly with promotions. Other benefits are:

a. Free ration every month.

b. Free medical benefits for the serving and their dependents.

c. Accommodation (quarters according to requirements, should be married and home should be out of Kathmandu valley)

d. Quality education for children (quota available at various army school across the country and NAIHS)

e. Allowances provided while in UN Peacekeeping Missions

f. Pension

7. Career development: GDMO's will be eligible for appearing for the Post-Graduation (MD, MS) entrance examinations inside and outside the country after the completion of three years of service. There are seats available from Armed Forces Medical College, Pune, India every year in different specialties. In addition, many national and international super-specialities courses can be done during the service period. However each courses come with service obligations, that is time period to serve in the Nepal Army Medical Corps.

8. Gender difficulties: Females have always been well represented in Nepal Army Medical Corps. Doctors are employed across all roles on the basis of the professional skills and competence. There are many misconceptions that it is very difficult to get into Army Medical Corps and it is more difficult for female doctors. However, the challenges in the job are alike for both males and females.

9. Miscellaneous: Besides the pomp and pageantry of wearing a uniform, there are many extracurricular opportunities like sports, expeditions, adventure, mountaineering etc. Also Officer's mess and bar are available for social events in all military units wherever posted.

The response of the participants was collected and the number of respondents stating a particular response was tabulated. The areas studied were: 
whether the students wanted to become a military doctor in Nepal Army and what was appealing and unappealing to them about becoming a military doctor. Then the participant's response was analysed.Statistical analysis was done by computing simple descriptive statistics (frequencies and percentages) for each survey question.

\section{RESULTS}

From the total (204) respondents (Boys-148, Girls-56), 64.7\% (132) desired to become a Military Doctor in Nepal Army whereas 14.7\% (30) did not like to join the Army Medical Services (Table 1). Among the responses, serving the nation (patriotic duty-88), opportunity for career development (MD/MS-76), for status (68), attraction to uniform and Army life (62), job security (52) and continuity of the parents (42) were identified as the most appealing about military service (Figure 1). The reasons for not choosing to become a military doctor were; prefer private independent practice (22), less pay/salary (20), rigorous demands of service (20), deployment consideration (14), service obligations (11) (Figure 2 ). About $21 \%$ of the total respondents were not sure about becoming a military doctor.

\section{DISCUSSION}

In Nepal, Government job in all sectors is attractive. ${ }^{2}$ The results of this study also depict similar attraction towards service in Nepal Army Medical Corps. In countries like India, UK and
Table 1. Showing the responses in number and in percentage

\begin{tabular}{|l|l|l|l|}
\hline \multirow{2}{*}{ Responses } & \multicolumn{2}{c}{ Respondents } & Total \\
\hline & \multicolumn{2}{|c|}{ Boys } & \multicolumn{1}{c|}{ Girls } \\
& \multicolumn{1}{|c|}{$(\%)$} & \multicolumn{1}{c|}{$\begin{array}{l}\text { Number } \\
(\%)\end{array}$} & $\begin{array}{l}\text { Number } \\
(\%)\end{array}$ \\
\hline $\begin{array}{l}\text { Like to become a } \\
\text { Military Doctor }\end{array}$ & $\begin{array}{l}92 \\
(62.16 \%)\end{array}$ & $\begin{array}{l}40 \\
(71.42 \%)\end{array}$ & $\begin{array}{l}132 \\
(64.70 \%)\end{array}$ \\
\hline $\begin{array}{l}\text { Don't like to } \\
\text { become a } \\
\text { Military Doctor }\end{array}$ & $\begin{array}{l}22 \\
(14.86 \%)\end{array}$ & $\begin{array}{l}8 \\
(14.28 \%)\end{array}$ & $\begin{array}{l}30 \\
(14.70 \%)\end{array}$ \\
\hline Not sure & $\begin{array}{l}34 \\
(22.97 \%)\end{array}$ & $\begin{array}{l}8 \\
(14.28 \%)\end{array}$ & $\begin{array}{l}42 \\
(20.58 \%)\end{array}$ \\
\hline Total & $\begin{array}{l}148 \\
(72.54 \%)\end{array}$ & $\begin{array}{l}56 \\
(27.45 \%)\end{array}$ & $\begin{array}{l}204 \\
(100 \%)\end{array}$ \\
\hline
\end{tabular}

USA being a much larger Military forces (Army, Air force, Navy) with diverse military objectives Military doctors have more rigorous demand of service and diverse deployment considerations. This comes along with better military benefits, pay/ salary and financial compensation in comparison to Nepal Army. 3,5,7,9

Becoming a Military doctor in the Indian Armed Medical Forces (IAMC) have some similarities with Nepal Army Medical Corps like joining eligibility criteria (MBBS), fitness level, age, benefits etc. ${ }^{4}$ However, in contrast to Nepal AMC, Indian AMC acquires their GDMOs as medical cadets in AFMC. The students join as a medical cadet and after completion of five years of medical

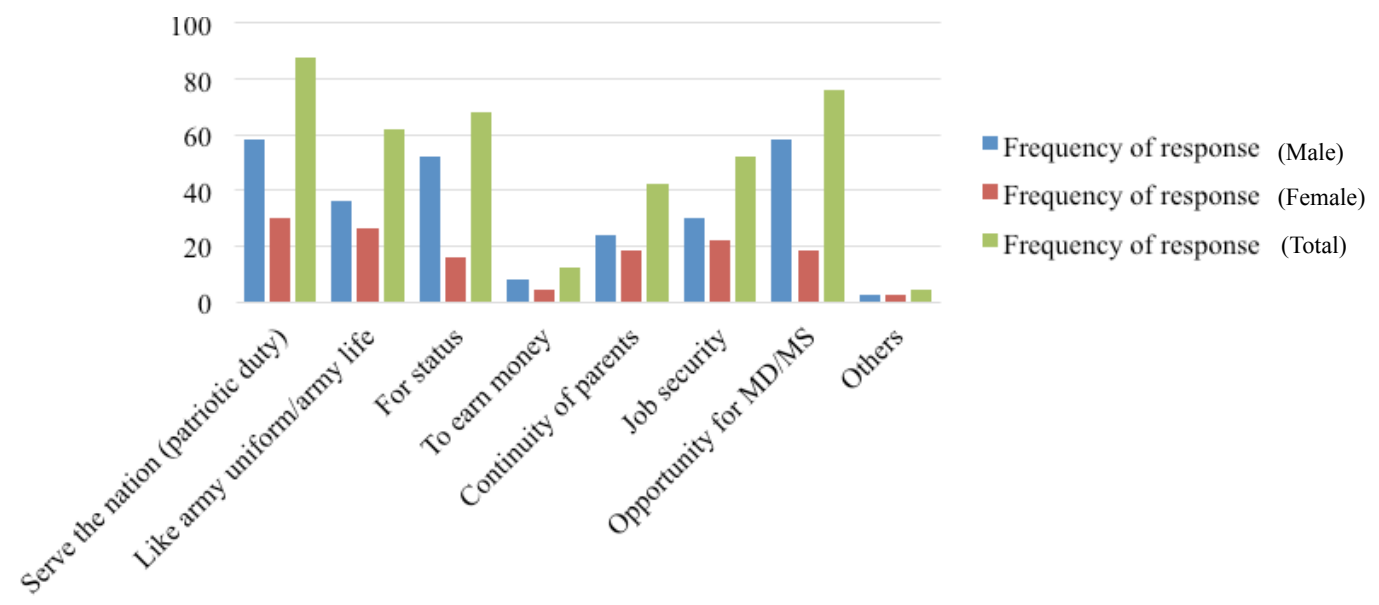

Figure 1. Military Service Questions/Response Options - Reasons to join Military Medical Service 


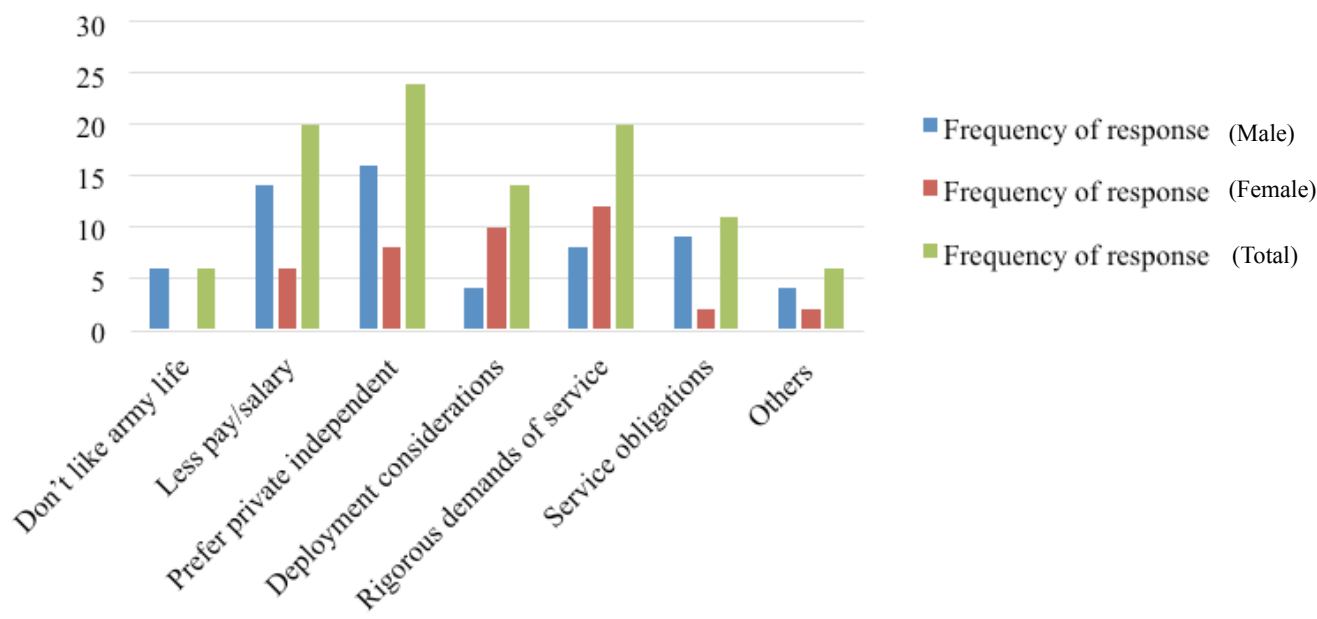

Figure 2. Military Service Questions/Response Options - Reasons not to join Military Medical Service

school graduate as MBBS, take up the rank of a Captain or equivalent and join the IAMC (Army, Air Force, Navy). ${ }^{5}$ Indian AMC also have provision of short service commission of two to eight years with an option to extend to permanent commission. $^{5}$

In the British Army, Medical Officers usually join the army during their first two years of medical school, after applying to the army officer selection board for consideration for a medical cadetship. This board tests physical fitness and mental acumen. Successful applicants achieve a short service commission of 10 years with the option to extend this if higher training is sought within the army. ${ }^{6}$ Most appealing to join as a medical doctor is financial sponsorship, job security, adventurous training and expeditions whereas unappealing is service obligations and diverse deployment.

In the American Army, three major accession programs recruit Military physicians. The Health Professions Scholarship Program (HPSP) and the Uniformed Services University of the Health Sciences (USUHS) recruit medical students and are responsible for generating more than $93 \%$ of the military physician workforce. ${ }^{7}$ The direct accessions program recruits practicing physicians utilising a number of incentives including the Health Professions Loan Repayment Program, the Financial Assistance Program, and substantial accession bonuses. ${ }^{8}$ About the US Military service Patriotic duty and serving service members are the most appealing whereas combat and deployment considerations are least appealing. ${ }^{9}$

The most chosen response option for joining the Military Medical Services in this study is Patriotic duty (Figure 1). This result is consistent with the appealing factor to become a Military Doctor in other countries. ${ }^{9}$ In Nepal obtaining post graduation (MD/MS) has become very competitive as well as expensive. Since the Nepal Army Medical Corps provides opportunities and financial sponsorship to their medical officers, this becomes an attractive factor for the doctors to join Nepal Army Medical Corps which is shown by the results (Figure 1). Historically, Nepalese feel pride in being an Army person so continuity of the family traditions is another strong factor of attraction of medical students to become a Military Doctor. Interestingly, despite various misconceptions regarding male and female difficulties in the military service greater percentage of the female students choose to become a military doctor (Table 1).

Reasons for not choosing to join Army Medical Services (Figure 2) includes rigorous demand of services, service obligations which are similar as with other countries Army Medical Services. Few other responses that are unappealing to become a Military Doctors in Nepal Army Medical Corps are regarding the family life (having to depart from family for long span of time and multiple postings) seems plausible according to the type of roles and responsibilities of a Military Doctor. Less pay/ 
salary was one of the reasons for not choosing to join Nepal Army Medical Services. However, this was not the case with other countries Army Medical services. ${ }^{3,8,9}$

Limitations to the study include; Only first and second year medical students were surveyed (third, fourth and fifth year students also could have been included) and questions related to the provided response options. Additionally, participants were volunteers, which reduce generalisability.

\section{CONCLUSIONS}

Job as a Military Doctor seems attractive to majority of the Medical students. Male and female medical students are equally interested towards it.
The most appealing about becoming a Military Doctor were patriotic duty, career development opportunity, job security, continuity of parents and for Status. Others include national and international travel, adventure, military benefits and diverse opportunities. Similarly the reasons for not opting to become a Military Doctor were, more lucrative job as a Civilian Doctor, less salary/pay and rigorous demand of service. Some didn't like the life in the army, bureaucracy issues and others had deployment problems.

\section{ACKNOWLEDGEMENT}

Special thanks to Maj Dr Rishi Pokhrel for his help during manuscript preparation

To cite this article: Shrestha BK, Shrestha R. Medical Students' Perception on Joining Military Medical Services: A Mixed Method Study. MJSBH. 2019;19(1):39-44.

Conflict of Interest: None declared

\section{REFERENCES}

1. Suprasanna Aryal, (2014), "On public service careers", Republica,27 Jan 2014)

2. Article: on July 13, 2016 of The Himalayan Times.

3. Nicola M. Becoming a military doctor in the British army. BMJ 2015; 350:h104.

4. https://www.careers360.com/question-how-to-become-a-doctor-in-indian-army-or-indian-airforce

5. https://www.joinindiannavy.gov.in/en/page/medical.html

6. Jones G.H, Wordsworth M. Military doctors: junior doctor experience in the British army. BMJ 2014; $349:$ Pg5729.

7. Dix M: Achievements of SOM Alumni. Uniformed Services University of the Health Sciences Journal. 2004;5:219_ 23.

8. Croasdale M. Military sweetens the deal to entice medical students. AMNews staff. 2008;7. Available from: http://www.ama-assn.org/amednews/2008/07/07/prsc0707.htm

9. Samuel L, Daniel J, Grigory C, Jeff A, John G. Military Physician Recruitment and Retention: A Survey of Students at the Uniformed Services University of the Health Sciences.Military Medicine. 2009; 174,5:529. 